\title{
Application of the region-time-length algorithm to study of earthquake precursors in the Thailand-Laos-Myanmar borders
}

\author{
P Puangjaktha and S PailopleE*®i \\ Morphology of Earth Surface and Advanced Geohazards in Southeast Asia Research Unit (MESA RU), \\ Department of Geology, Chulalongkorn University, Bangkok 10330, Thailand. \\ *Corresponding author. e-mail: Pailoplee.S@gmail.com
}

MS received 10 March 2017; revised 9 August 2017; accepted 22 August 2017; published online 27 March 2018

In order to examine the precursory seismic quiescence of upcoming hazardous earthquakes, the seismicity data available in the vicinity of the Thailand-Laos-Myanmar borders was analyzed using the RegionTime-Length (RTL) algorithm based statistical technique. The utilized earthquake data were obtained from the International Seismological Centre. Thereafter, the homogeneity and completeness of the catalogue were improved. After performing iterative tests with different values of the $r_{0}$ and $t_{0}$ parameters, those of $r_{0}=120 \mathrm{~km}$ and $t_{0}=2 \mathrm{yr}$ yielded reasonable estimates of the anomalous RTL scores, in both temporal variation and spatial distribution, of a few years prior to five out of eight strong-to-major recognized earthquakes. Statistical evaluation of both the correlation coefficient and stochastic process for the RTL were checked and revealed that the RTL score obtained here excluded artificial or random phenomena. Therefore, the prospective earthquake sources mentioned here should be recognized and effective mitigation plans should be provided.

Keywords. Earthquake catalogue; RTL algorithm; seismic quiescence; earthquake precursor; Thailand-Laos-Myanmar borders.

\section{Introduction}

Not only the interplate and intraslab of the Sumatra-Andaman Subduction Zone, but also the Mainland Southeast Asia has been recognized as one of the most seismically active regions, especially the areas along the Thailand-Laos-Myanmar borders (TLMB; Pailoplee and Choowong 2013, 2014). Seismotectonically, TLMB was defined as an intraplate earthquake source due to the presentday Indo-Australian and Eurasian plate collision (Fenton et al. 2003). A number of seismogenic faults delineate dominantly into two strikes, i.e., northeast-southwest (e.g., Mengxing, Nam Ma, and Mae Chan fault zones) and northwest-southeast (e.g., Mae Hong Sorn-Tak fault zone) directions. These faults move presently in dextral (rightlateral) and sinistral (left-lateral) slip on northwest- and northeast-striking faults, respectively (Polachan et al. 1991; Fenton et al. 2003). Based on a decade of GPS survey in the Mainland Southeast Asia, Simons et al. (2007) estimated the maximal strike-slip motion of faults in the TLMB around $4 \pm 2 \mathrm{~mm} / \mathrm{yr}$ conforming to the morphotectonic evidences mentioned by Lacassin (1998), Fenton et al. (2003), and Iwakuni et al. (2004). Seismically, more than eight strong-tomajor earthquakes $\left(M_{w} \geq 6\right)$ have occurred in this area during the three decades since 1983 (figure 1). In addition, a number of major cities, 

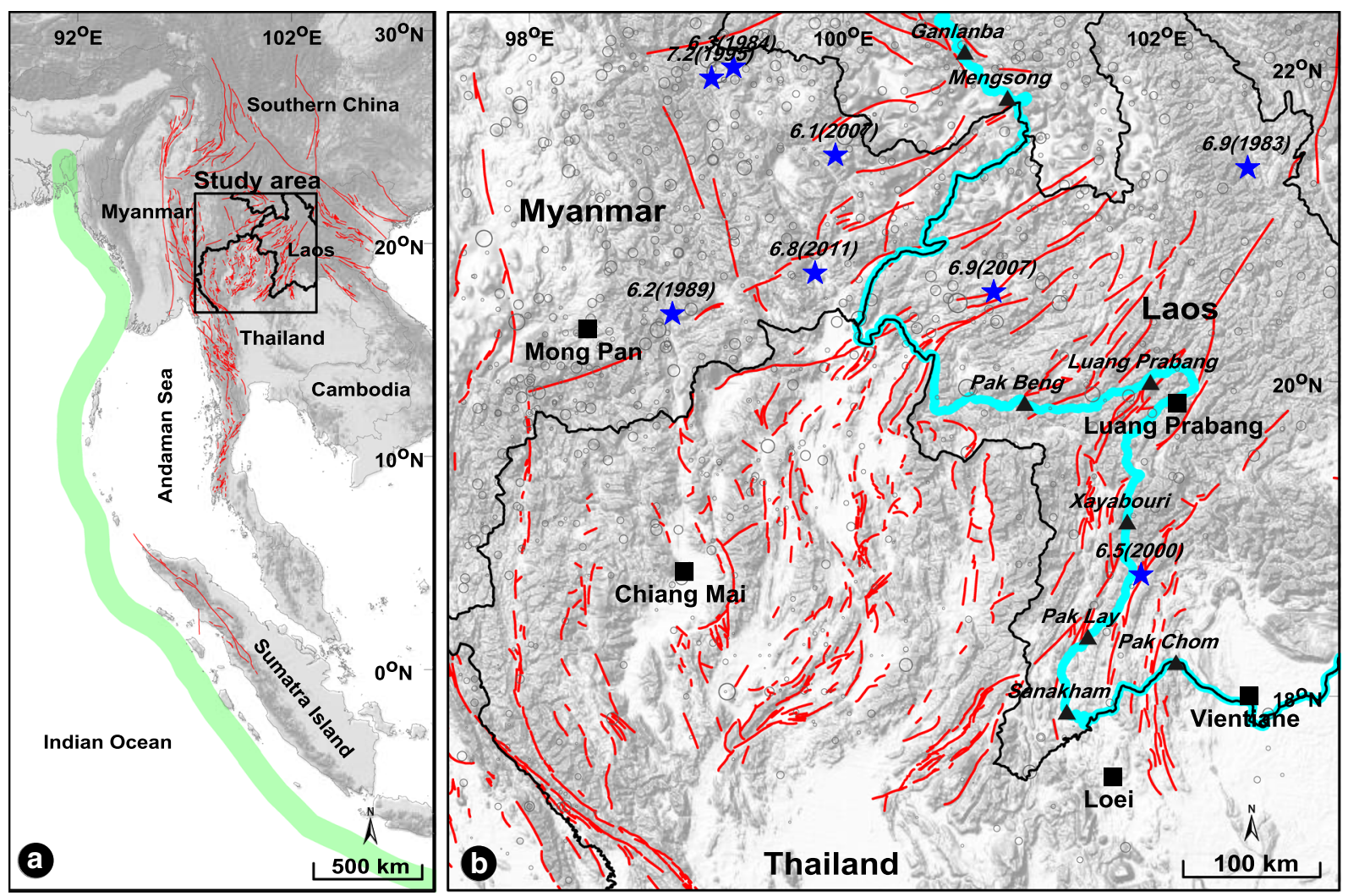

Figure 1. (a) Map of Mainland Southeast Asia showing the Sumatra-Andaman Subduction Zone (thick green line) and seismogenic faults as compiled by Pailoplee et al. (2009) (thin red lines). The study area focuses in the TLMB bounded by the square. (b) Shaded relief map of the TLMB showing the distribution of earthquakes with $\mathrm{M}_{\mathrm{w}} \geq 6.0$ that have occurred during 1983-2011 (blue stars). The seismogenic fault lines, major cities and hydropower dams are expressed as red lines, black squares and black triangles, respectively. The grey circles denote the improved completeness earthquake data utilized in this RTL investigation.

and the mega-scheme of hydropower dams along the Mekong mainstream, are distributed in this region and so the situation of earthquake activities and hazards in this region should be clarified.

With respect to the statistical seismology, the frequency-magnitude distribution model (FMD; Gutenberg and Richter 1944) coefficient a- and b-values have previously been evaluated for the TLMB region (Pailoplee et al. 2013). Using the relationships proposed by Yadav et al. (2011), Pailoplee et al. (2013) then systematically converted the obtained a- and b-values and mapped the earthquake activities, in terms of (i) the possible maximum magnitude, (ii) return period and (iii) the probabilities of earthquake occurrences, in the TLMB region. In addition, based only on the spatial distribution of the b-value, Pailoplee et al. (2013) proposed two prospective areas that might generate upcoming major earthquakes. These were (i) the northern part of Mong Pan, eastern Myanmar, and (ii) the Pak Beng and Luang Prabang dams, northern Laos.
At present, according to the compilation of Tiampo and Shcherbakov (2011), various methods of the seismicity-based earthquake forecasting have been proposed, such as the accelerating moment release (Jordan and Jones 2010), pattern informatics (Holliday et al. 2006), seismicity rate change or $\mathrm{Z}$ value (Wiemer and Wyss 1994) and the regiontime-length algorithm (RTL; Huang et al. 2001; Gentili 2010). Among these, the RTL algorithm is one of the more effective methods because it can successfully find the precursory RTL score prior to various hazardous earthquakes and regions, such as the $\mathrm{M}_{\mathrm{w}} 7.2$ Kobe earthquake in 1995 (Huang et al. 2001), Mw 7.8 Nemuro peninsula earthquake in 2000 (Huang and Sobolev 2002), $\mathrm{M}_{\mathrm{w}}$ 7.6 Chi-Chi earthquake in 1999 (Chen and $\mathrm{Wu} 2006$ ) and the $\mathrm{M}_{\mathrm{w}} 4.8$ Aeolian Archipelago earthquake in 2010 (Gambino et al. 2014). Therefore, in order to constrain the prospective areas of the upcoming hazardous earthquakes evaluated from the b-value by Pailoplee et al. (2013), the RTL algorithm was evaluated in the vicinity 
of the TLMB, which is the main aim of this study.

\section{The RTL algorithm}

According to Sobolev and Tyupkin (1997, 1999), the RTL algorithm is a useful method of statistical seismology that was developed recently to find out the existence of the precursory seismicity changes (quiescent and activation stages) prior to the occurrence of the main shock (Sobolev 1995). Mathematically, the three functions of $\mathrm{R}$ (region), $\mathrm{T}$ (time) and L (rupture length) can be expressed as equations (1-3), respectively:

$$
\begin{aligned}
& R(x, y, z, t) \\
& \quad=\left[\sum_{i=1}^{n} \exp \left(-\frac{r_{i}}{r_{0}}\right)-R_{b g}(x, y, z, t)\right], \\
& T(x, y, z, t) \\
& \quad=\left[\sum_{i=1}^{n} \exp \left(-\frac{t-t_{i}}{t_{0}}\right)-T_{b g}(x, y, z, t)\right], \\
& L(x, y, z, t) \\
& \quad=\left[\sum_{i=1}^{n} \exp \left(-\frac{l_{i}}{r_{i}}\right)-L_{b g}(x, y, z, t)\right],
\end{aligned}
$$

where $(x, y, z, t)$ denotes the considered location and time, $r_{i}$ is the distance between the location of $(x, y, z)$ and the focus of the $i$ th earthquake, $t_{i}$ is the origin time of the $i$ th earthquake and $l_{i}$ is the length of surface fault rupture according to the $i$ th earthquake related directly to the earthquake magnitude (Wells and Coppersmith 1994). The terms $R_{b g}(x, y, z, t), T_{b g}(x, y, z, t)$ and $L_{b g}(x$, $y, z, t)$ are the background values of $R(x, y, z, t)$, $T(x, y, z, t)$ and $L(x, y, z, t)$, respectively, while the parameters $r_{0}$ and $t_{0}$ are the characteristic distance and time span that are free to vary in any specific study area. The parameter $n$ is the number of earthquakes with a magnitude $\geq$ the magnitude of completeness (Mc; Woessner and Wiemer 2005), $2 r_{0}=R_{\max } \geq r_{i}$, and $2 t_{0}=T_{\max } \geq t-t_{i}$. From these three functions ( $\mathrm{R}, \mathrm{T}$ and $\mathrm{L})$, the $V_{R T L}(x, y$, $z, t)$ or RTL score can be complied as equation (4).

$$
\begin{aligned}
V_{R T L}(x, y, z, t)= & \frac{R(x, y, z, t)}{R(x, y, z, t)_{\max }} \\
& \times \frac{T(x, y, z, t)}{T(x, y, z, t)_{\max }} \\
& \times \frac{L(x, y, z, t)}{L(x, y, z, t)_{\max }} .
\end{aligned}
$$

In a given location $(x, y, z)$ and time $(t)$, the RTL score varies between -1 and 1. Seismically, $V_{R T L}=0$ implies the normal activity of the seismicity. Meanwhile, $V_{R T L}>0$ and $<0$ represent a seismic activation and quiescence, respectively.

\section{Dataset and completeness}

In this investigation of the RTL algorithm, the instrumental earthquake records of the International Seismological Centre (ISC; http://www.isc. ac.uk/) were employed as the main dataset. Within a $300-\mathrm{km}$ radius extended from the study area (figure 1), there were 20,699 recorded earthquakes with a magnitude range of 1.0-7.7 that were reported during 1960.03-2015.00. Almost all of these earthquakes had the focal depth of $<40 \mathrm{~km}$, which implies they were shallow crustal earthquakes from the intraplate seismotectonic regime of the study area. With respect to the scale of the earthquake magnitude, the earthquake data was reported variously as the moment magnitude $\left(\mathrm{M}_{\mathrm{w}}\right)$, body-wave magnitude $\left(m_{b}\right)$ and surface-wave magnitude $\left(M_{s}\right)$. Based on those events that were reported simultaneously in the different magnitude scales, the empirical relationships of $\mathrm{M}_{\mathrm{w}}-\mathrm{m}_{\mathrm{b}}$ and $\mathrm{M}_{\mathrm{w}}-\mathrm{M}_{\mathrm{s}}$ were contributed (figure $2 \mathrm{a}$ and $\mathrm{b}$ ). Thereafter, in order to homogenize the scale of the earthquake magnitude, events reported in the $m_{b}$ or $M_{s}$ scale were converted to the $M_{w}$ scale according to the contributed relationships.

In order to collect only the mainshock earthquakes, so as to represent exactly the seismotectonic activities, the MW homogenized earthquake catalogue was then de-clustered using the algorithm introduced by Gardner and Knopoff (1974), and implemented in the ZMAP software (Wiemer 2001). This resulted in 1605 earthquake clusters and 17,156 events being defined as foreshocks or aftershocks and were excluded from this study, leaving 3543 residual events that were defined as the main shocks.

The earthquake recording process, and hence the earthquake data in the catalogue, is performed by different analytical processes and this can affect the completeness and homogeneity of the catalogue (Wyss 1991; Zúñiga et al. 2000). In order to remove these types of artifacts in the database, the GENAS algorithm (Habermann 1983, 1987) was performed throughout all magnitude ranges and recording time span of the catalogue. As a result, a total of 1430 earthquakes in the 

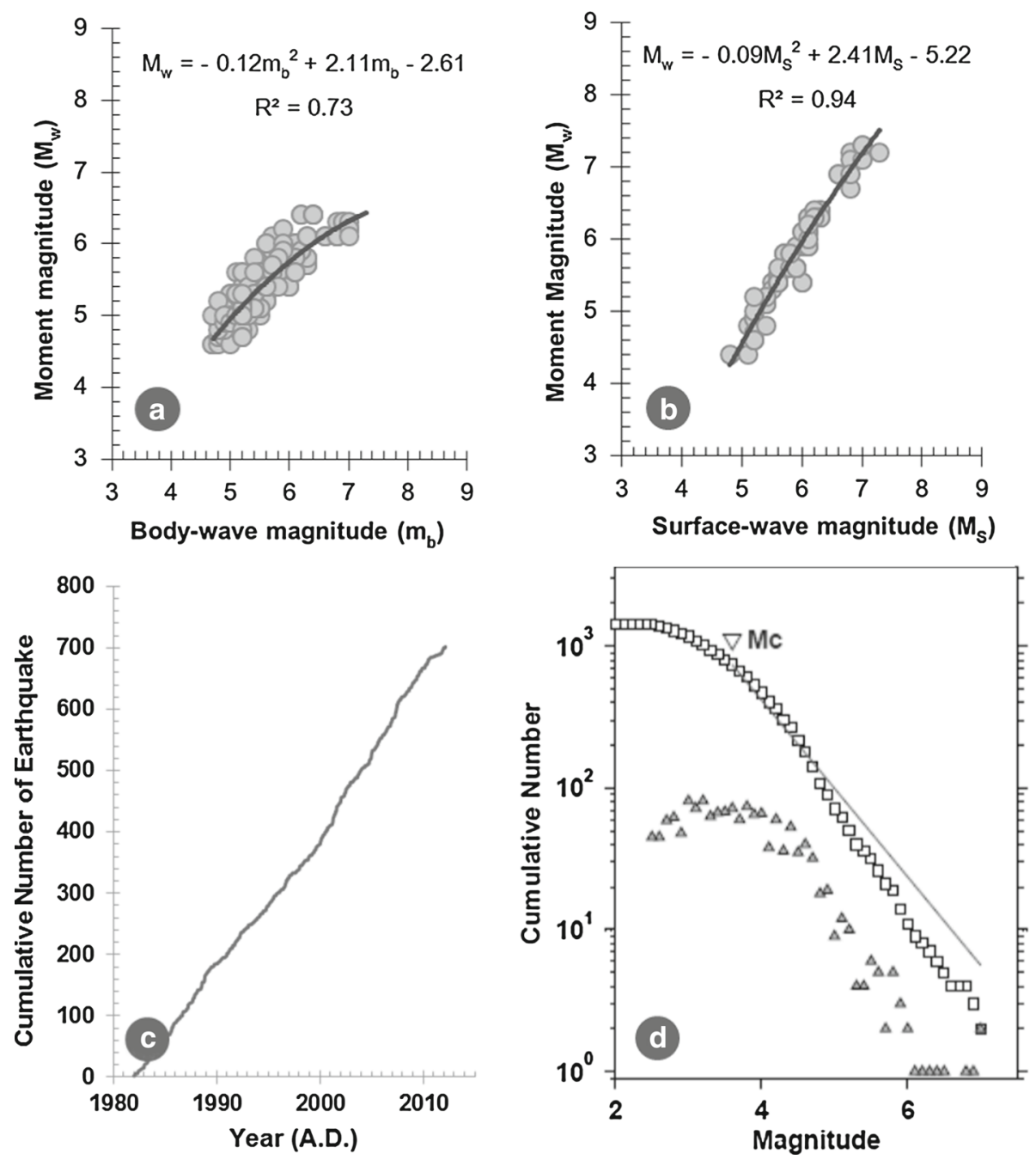

Figure 2. Graphs showing the relationships of (a) $M_{w}-m_{b}$ and (b) $M_{w}-M_{s}$ analyzed from the available earthquake data in the TLMB. (c) Cumulative number of earthquakes with $\mathrm{M}_{\mathrm{w}} \geq 2.5$ recorded during 1983.39-2011.06. (d) The FMD plot of the bulk completeness earthquake data. Triangles and squares illustrate the total and cumulative number of seismicity data in each magnitude, respectively.

dataset for 1983.39-2011.06 with an $\mathrm{M}_{\mathrm{w}} \geq 2.5$ were determined as the completeness data and likely to have been excluded from man-made artifacts implied by the straight line of the cumulative number of earthquakes (figure 2c).

As mentioned earlier, the earthquake data available for RTL algorithm investigation should have a magnitude equal to or larger than the Mc. Therefore, in the final step of the earthquake catalogue improvement, the FMD of the bulk seismicity data were plotted (figure $2 \mathrm{~d}$ ). According to the entire magnitude range method (Woessner and Wiemer 2005), the Mc was estimated at 3.6 yielding a total of 937 earthquakes with a $\mathrm{M}_{\mathrm{w}} \geq 3.6$ during 1983.39-2011.06, and these were utilized in this RTL investigation.

\section{Retrospective tests}

\subsection{Temporal investigation}

In order to define the relationship between the RTL score and the subsequent occurrence of a hazardous earthquake at a given locality, the RTL algorithm was investigated retrospectively in both temporal and spatial aspects at the epicenters of eight strong-to-major earthquakes $\left(\mathrm{M}_{\mathrm{w}} \geq 6.0\right)$ previously recorded within the TLMB (table 1 ). The outcome obtained here is the characteristic parameters $\left(r_{0}\right.$ and $t_{0}$, related to $R_{\max }$ and $T_{\max }$, respectively), suitable for detecting the precursory RTL score generated prior to the hazardous earthquake in the TLMB. To achieve this, $r_{0}$ was varied from 
40 to 150 at $5 \mathrm{~km}$ intervals, and $t_{0}$ varied from 0.5 to 5 yr in 0.05 yr intervals. Hence, 1760 (22 $\times 80$ ) conditions of the characteristic parameters were considered iteratively for each earthquake case study.

After iterative tests, the results revealed that the characteristic distance $r_{0}$ of $120 \mathrm{~km}\left(R_{\max }=240\right.$ $\mathrm{km})$ and time $t_{0}$ of $2 \mathrm{yr}\left(T_{\max }=4 \mathrm{yr}\right)$ were the most successful conditions to find out the anomalous RTL score related for five of the eight recognized earthquakes (table 1). With respect to the retrospective temporal investigation, the RTL score was evaluated every 10 days from the beginning of available seismicity data (1983), through the occurrence time of each earthquake considered. The temporal variations of the RTL score for the five successful case studies are shown in figure 3. Due to insufficient seismicity data, the RTL algorithm cannot detect any anomalous RTL score before the occurrence of the $\mathrm{M}_{\mathrm{w}} 6.9$ earthquake in $1983, \mathrm{M}_{\mathrm{w}} 6.3$ earthquake in 1984 and the $\mathrm{M}_{\mathrm{w}} 6.2$ earthquake in 1989 (table 1).

For example, in figure 3(a), the temporal variations of RTL score determined at the location of the $\mathrm{Mw} 7.2$ earthquake revealed the seismic quiescence started in 1992.35. After that, the RTL score decreased immediately and reached its minimum in 1992.39 (RTL score $=-1.0$ ) before rising rapidly to a background value in 1992.85 and remaining stable until the earthquake was generated on July 11th, 1995 (3.1 yr after the quiescence was found). At the location of the $\mathrm{Mw} 6.5$ earthquake posed on June 7th, 2000 (figure 3b), the RTL score was steady between 1983.39 and 1992.73, then varied slightly during 1992.74-2000.06 before it decreased instantly to the lowest level in 2000.40 (RTL score $=-0.90)$. However, the Mw 6.5 earthquake occurred during the quiescent stage. In figure 3(c), the RTL score curve indicated clearly three quiescent stages (i.e., 1989.79-1991.81, 1991.89-1992.73 and 2003.93-2004.81) and three activation stages (i.e., 1987.36-1988.97, 1993.581995.65 and 1995.76-1996.76). From the minimum RTL score $(-0.6 .5)$ the quiescent stage of 2003.93-2004.81 was defined as the precursor of the $\mathrm{Mw} 6.9$ main shock with a time delay of 3.4 yr after the end of quiescent stage (on May 16, 2007). Based on figure $3(\mathrm{~d})$, the seismic quiescence started decreasing in 1995.45 and reached its minimum in 1995.65 (RTL score $=-0.65$ ). In addition, the RTL score indicated an activation stage during 1999.25-2000.21 with a maximum RTL score of 0.40. After the activation stage,

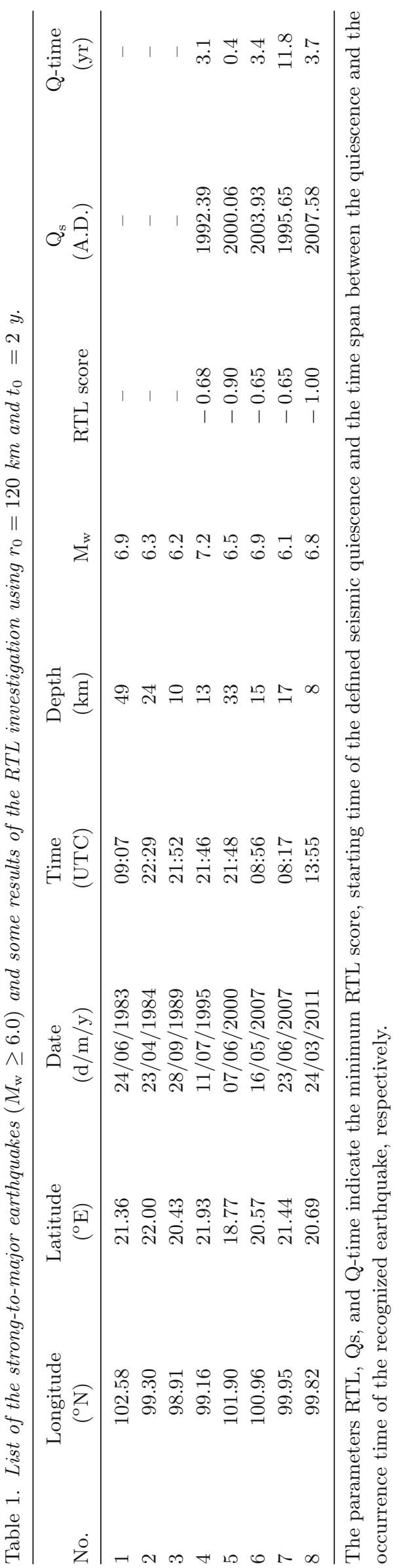


(a) $\mathrm{M}_{\mathrm{w}}-7.2$ earthquake, July $11^{\text {th }}, 1995$

Q stage: $1992.35-1992.85$

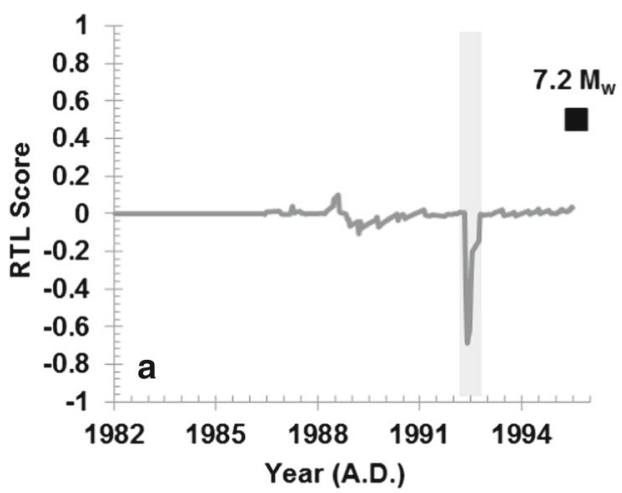

(c) $\mathrm{M}_{\mathrm{w}}-6.9$ earthquake, May $16^{\text {th }}, 2007$

Q stage: 2003.93-2004.81

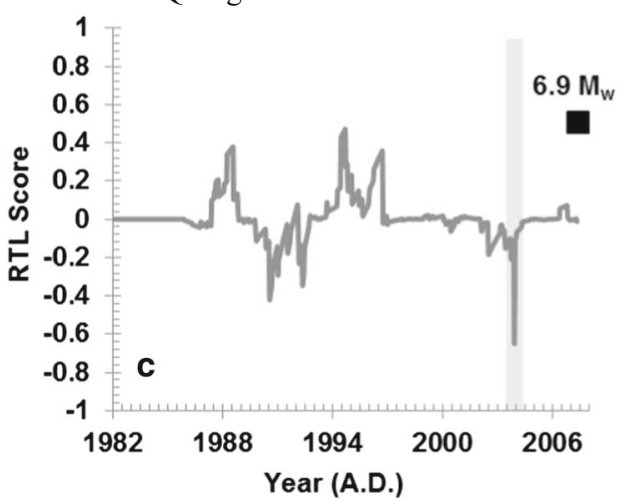

(e) $\mathrm{M}_{\mathrm{w}}-6.8$ earthquake, March $24^{\text {th }}, 2011$

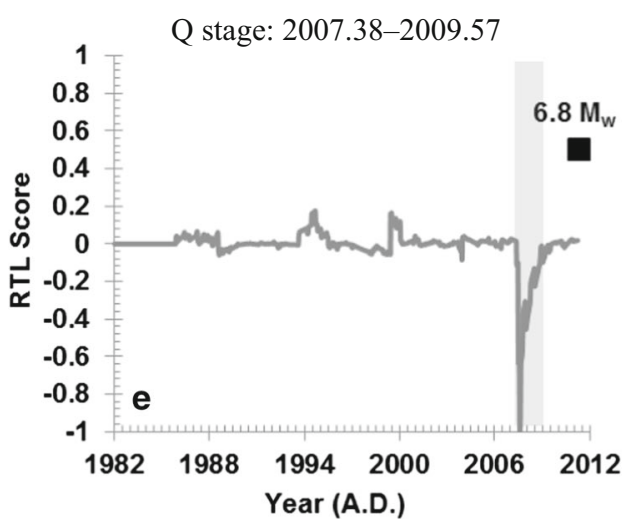

(b) $\mathrm{M}_{\mathrm{w}}-6.5$ earthquake, June $7^{\text {th }}, 2000$

Q stage: $2000.06-2000.40$

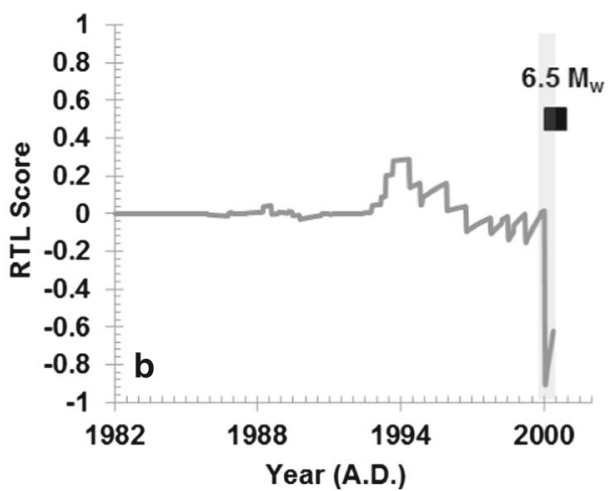

(d) $\mathrm{M}_{\mathrm{w}}-6.1$ earthquake, June $23^{\text {th }}, 2007$

Q stage: 1995.45-1996.26

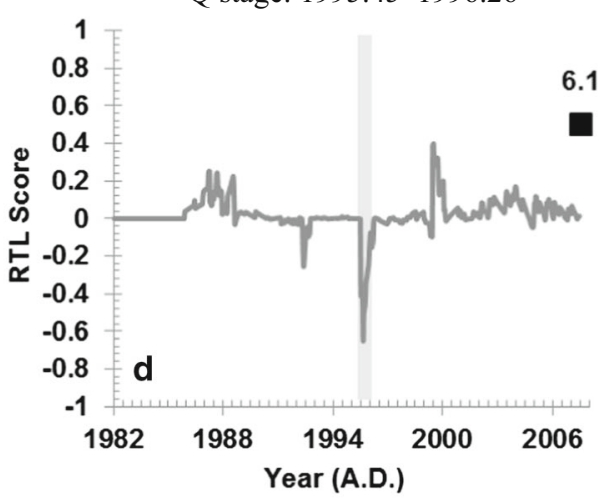

Figure 3. Temporal variation of the RTL score (grey line) of five out of eight strong-to-major earthquakes recognized in the retrospective test. The black square indicates the origin time of each strong-to-major earthquake.

the RTL curve has a small variant for 7.3 yr before the occurrence of the Mw 6.1 earthquake on June 23, 2007. Finally, for figure 3(e), the variation in the RTL score illustrated clearly the seismic quiescence. The RTL started decreasing at 2007.38 and reached its minimum at 2007.58 before returning gradually to the background rate at 2009.57. Thereafter, 3.7 yr later, the $\mathrm{Mw} 6.8$ earthquake occurred on March 24, 2011.

\subsection{Spatial investigation}

In order to re-check the capability of using the RTL algorithm for earthquake forecasting, the RTL score was also investigated spatially. At first, the study area (figure 1) was gridded with a $0.2^{\circ} \times$ $0.2^{\circ}$ grid interval spacing. At each grid node, the temporal variation of the RTL score was evaluated according to equations (1-4). In order to spatially 
(a) $\mathrm{M}_{\mathrm{w}}-7.2$ earthquake, July $11^{\text {th }}, 1995$

Epicenter: $21.93^{\circ} \mathrm{E}, 99.16^{\circ} \mathrm{N}$

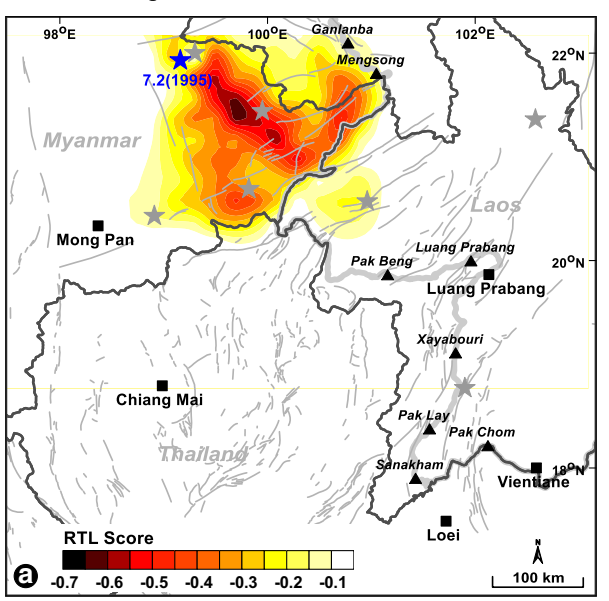

(c) $\mathrm{M}_{\mathrm{w}}-6.9$ earthquake, May $16^{\text {th }}, 2007$

Epicenter: $100.96^{\circ} \mathrm{N}, 20.57^{\circ} \mathrm{E}$

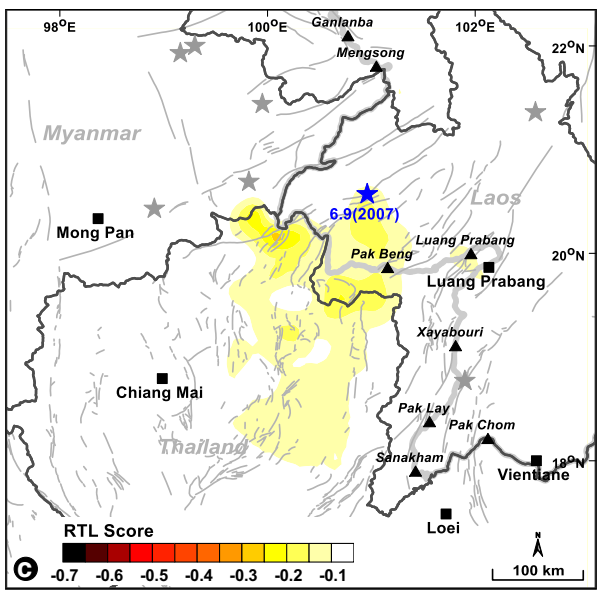

(e) $\mathrm{M}_{\mathrm{w}}-6.8$ earthquake, March $24^{\text {th }}, 2011$

Epicenter: $99.82^{\circ} \mathrm{N}, 20.69^{\circ} \mathrm{E}$

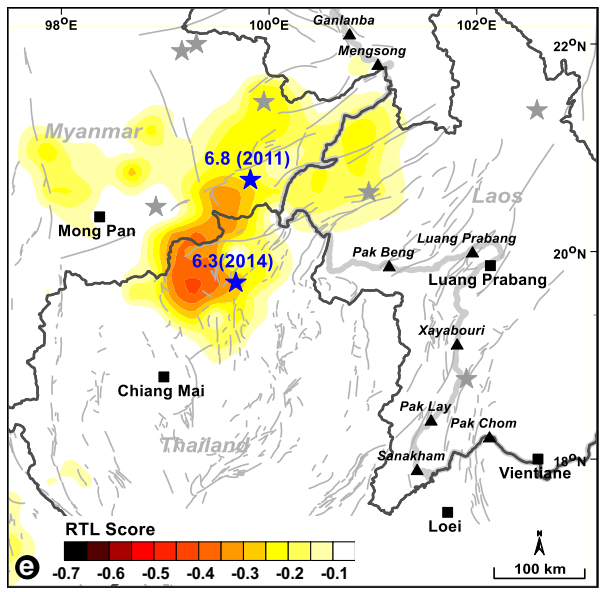

(b) $\mathrm{M}_{\mathrm{w}}-6.5$ earthquake, June $7^{\text {th }}, 2000$

Epicenter: $18.77^{\circ} \mathrm{E}, 101.90^{\circ} \mathrm{N}$

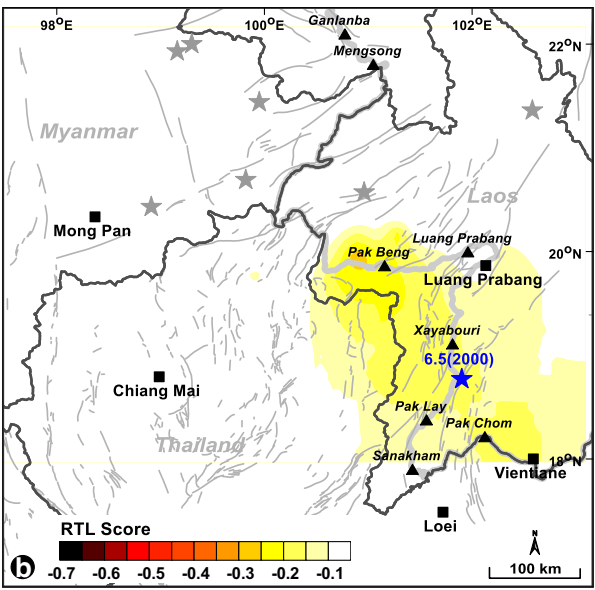

(d) $\mathrm{M}_{\mathrm{w}}-6.1$ earthquake, June $23^{\text {th }}, 2007$

Epicenter: $99.95^{\circ} \mathrm{N}, 21.44^{\circ} \mathrm{E}$

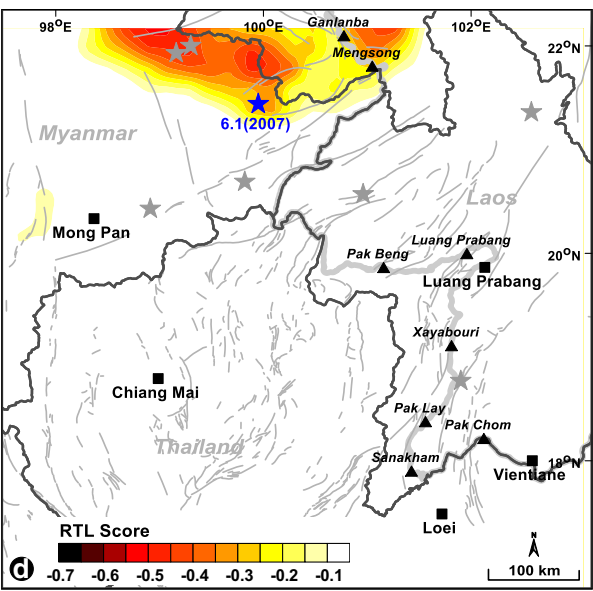

(f) b value map using completeness seismicity data recorded during 1984-2010 (Pailoplee et al. 2013)

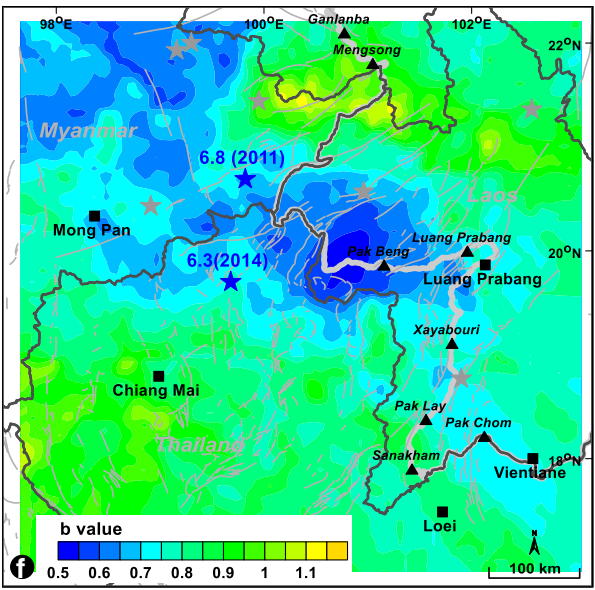

Figure 4. (a-e) Map of the TLMB showing the spatial distribution of the RTL score at the time span of the seismic quiescence of each case study (same five earthquakes as in figure 3). The lower the RTL score, the more quiescent the seismicity. The epicenter of the individual recognized earthquake is shown as a blue star. (f) Spatial distribution of the FMD b-value as analyzed from the earthquake data recorded during 1984-2010 (Pailoplee et al. 2013). Blue stars indicate the Mw 6.8 earthquake on March 24th, 2011 and $\mathrm{M}_{\mathrm{L}}-6.3$ earthquake on May 5th, 2014, respectively. 
map the RTL score, the $Q$ parameter (Huang 2004) was performed, as expressed in equation (5):

$$
\begin{aligned}
Q & \left(x, y, z, t_{1}, t_{2}\right) \\
& =\left[\sum_{i=1}^{n} V_{R T L}\left(x, y, z, t_{i}\right)\right],
\end{aligned}
$$

where $Q\left(x, y, z, t_{1}, t_{2}\right)$ is the $Q$ parameter obtained by averaging the RTL score during the time window of interest $\left(t_{1}, t_{2}\right)$, and $n$ is the mean the number of the RTL-score data estimated during the time span of $t_{1}-t_{2}$. Based on the quiescent time $\left(t_{1}-t_{2}\right)$ obtained from the temporal investigation (figure 3), the $Q$ parameter of each grid node was calculated, contoured and mapped as shown in figure 4 .

For example, in figure 4(a), the distribution of the $Q$ parameter averaged over the time span from 1992.35-1992.85 revealed the seismic quiescence covered around $200 \mathrm{~km}^{2}$ over the eastern part of Myanmar (around $150 \mathrm{~km}$ southwest of the Mengsong city). As complied by Pailoplee et al. (2009), this anomalous area overlaps on the Jinghong (Lacassin 1998), Mengxing (Lacassin 1998) and Nam Ma (Morley 2007) seismogenic fault zones. For the epicenter of the Mw 7.2 earthquake posed on July 11, 1995, the location of the minimum RTL score was in the southeastern part and not far from the earthquake epicenter (figure 4a). Figure 4(b) shows the $Q$ parameters for the time span 2000.062000.40 , where a weak anomaly was generated in a $200 \mathrm{~km}^{2}$ area over the northwestern part of Laos, including the Thailand-Laos border. This anomaly was located in the vicinity of the Dein Bein Fu (Zuchiewicz et al. 2004) and Nam Peng (Charusiri et al. 1999) fault zones. The $\mathrm{Mw} 6.5$ earthquake posed on June 7, 2000 was located at the southern part of Luang Prabang and was some $180 \mathrm{~km}$ away from the location of the minimum RTL area (figure 4b).

With respect to the $6.9 \mathrm{M}_{\mathrm{w}}$ earthquake posed on May 16, 2007, the quiescent time estimated from temporal investigation was in the range of 2003.932004.81, with the spatial distribution of the RTL score shown in figure 4(c). There were some weakly seen quiescent anomalies in the vicinity of the Pak Beng dam. However, the epicenter of the earthquake was located at the northern part of the Pak Beng dam (figure 4c). In figure 4(d), covering the quiescent period of 1995.45-1996.26, a prominent anomaly occurred around $300 \mathrm{~km}$ along the east of Myanmar where the Jinghong fault zone is defined to be located. In addition, the epicenter of the $6.1 \mathrm{M}_{\mathrm{w}}$ earthquake that occurred on June 23, 2007 was located within the defined RTL anomalies (figure 4d). Finally, in figure 4(e), the spatial distribution of the RTL score during 2007.38-2009.57 revealed the seismic quiescence area covered around $300 \mathrm{~km}^{2}$ over of the ThailandMyanmar border. In particular, the minimum RTL score delineates the northern part of Chiang Mai city and is close to the Mae Chan fault zone (Fenton et al. 2003). Within 5 yr after these anomalies (2010-2015), there were two hazardous earthquakes posed in the vicinity (figure 4e), being the Mw 6.8 Tarlay earthquake on March 24, 2011 (Wang et al. 2014) and the $\mathrm{M}_{\mathrm{L}}$ 6.3 Mae Lao earthquake on May 5, 2014 (Ornthammarath et al. 2015).

\section{Discussion}

\subsection{Correlation coefficient of the characteristic RTL parameters}

In order to constrain the significance of the selected characteristic parameters $\left(r_{0}=120 \mathrm{~km}\right.$ and $t_{0}=$ $2 \mathrm{yr}$ ), the temporal variations of the RTL scores were also investigated by increasing/decreasing $r_{0}$ by $25 \mathrm{~km}$ and increasing/decreasing $t_{0}$ by $0.5 \mathrm{yr}$ from the parameters used in this study. Thereafter, the correlation coefficient of each pair of the utilized and varied parameters was evaluated according to the method of Huang (2005). For example, the case study of the Mw 6.8 earthquake on March 24, 2011 (figure 5a and table 2), gave correlation coefficients that ranged from 0.82 to 0.90 , implying that all the varied cases listed in table 2 correlated at a significance of 0.05 (Huang 2005). Therefore, the selected characteristic parameters were meaningful and the quiescence founded in the TLMB is not due to the artifact of free parameter selection.

\subsection{Stochastic test of the RTL score}

In order to check in more detail that the anomalous quiescence obtained in this study was not due to the randomness of the earthquake data, the stochastic test was used according to Huang et al. (2002). To achieve this, the earthquake catalogue was synthesized randomly 10,000 times in the same space and recording time as the observed catalogue used in this study. Then for each synthesized catalogue, the RTL score was computed at the 

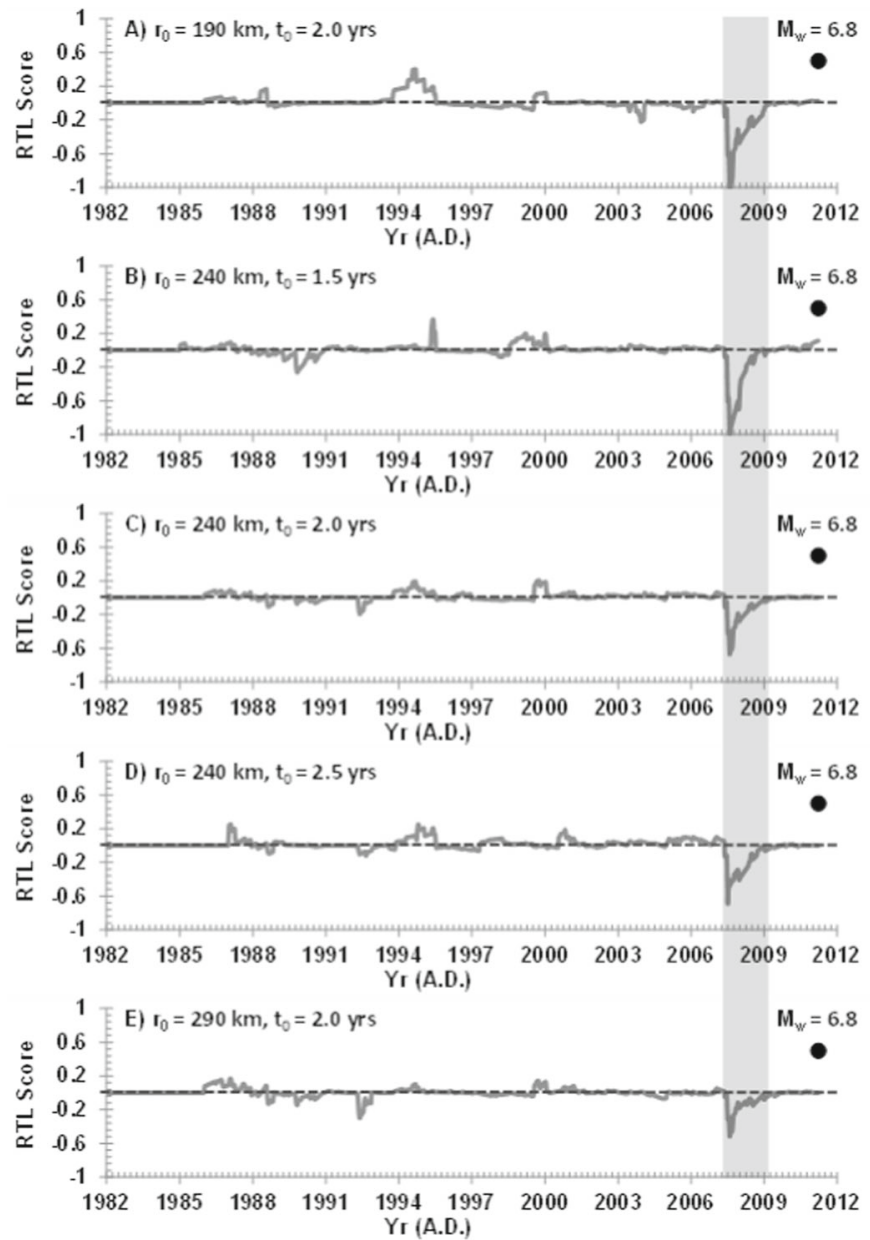

a

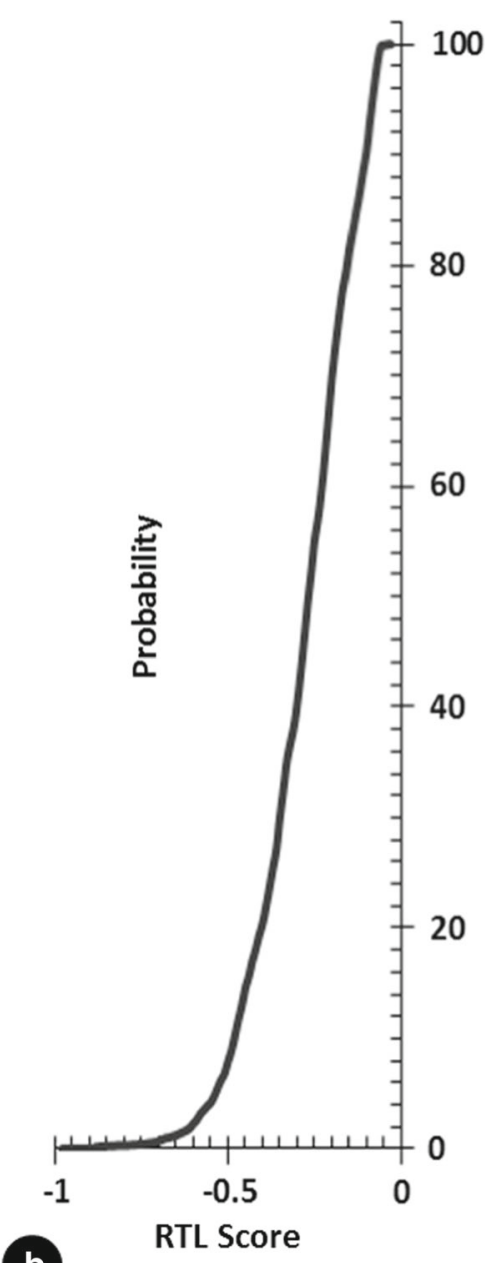

Figure 5. (a) Temporal variation of the RTL score (grey lines), as evaluated from different characteristic parameters. Black circles denote the origin time of the Mw 6.8 earthquake generated on March 24th, 2011. Grey shade indicates the period of quiescence mentioned. (b) Stochastic tests showing the probability of occurrence (\%) of RTL scores at the epicenters of the Mw 6.8 earthquake generated on March 24th, 2011.

Table 2. Examples of correlation coefficients of the RTL scores obtained with different utilized $r_{0}$ and $t_{0}$ values for the $M_{w} 6.8$ earthquake on March 24, 2011. Case A represents the parameters utilized in this study whereas case B represents the other nearby parameters recognized for correlation.

\begin{tabular}{lcccc}
\hline Case A & \multicolumn{4}{l}{$r_{0}=120 \mathrm{~km}, t_{0}=2.0 \mathrm{yr}$} \\
\cline { 2 - 5 } Case B & $r_{0}=95 \mathrm{~km}$ & $r_{0}=145 \mathrm{~km}$ & $t_{0}=1.5 \mathrm{yr}$ & $t_{0}=2.5 \mathrm{yr}$ \\
\hline Correlation of A and B & 0.87 & 0.82 & 0.82 & 0.90 \\
\hline
\end{tabular}

location of each of the five strong-to-major earthquakes (table 1), so for each earthquake location the probability of occurrence at each level of the RTL score was evaluated. The results indicated that the probability of obtaining an RTL score mentioned as an anomaly in this study (RTL score $<-0.65$ ) was $<10 \%$ (figure $5 \mathrm{~b}$ ), and so there was a $>90 \%$ chance that almost all the anomalies obtained here were not the result of a stochastic process or random phenomena.

\subsection{The starting time of the seismic quiescence}

Previous research have almost all proposed that the RTL algorithm is effective for intermediateterm earthquake forecasting (e.g., Sobolev and Tyupkin 1997; Huang et al. 2001; Huang and 


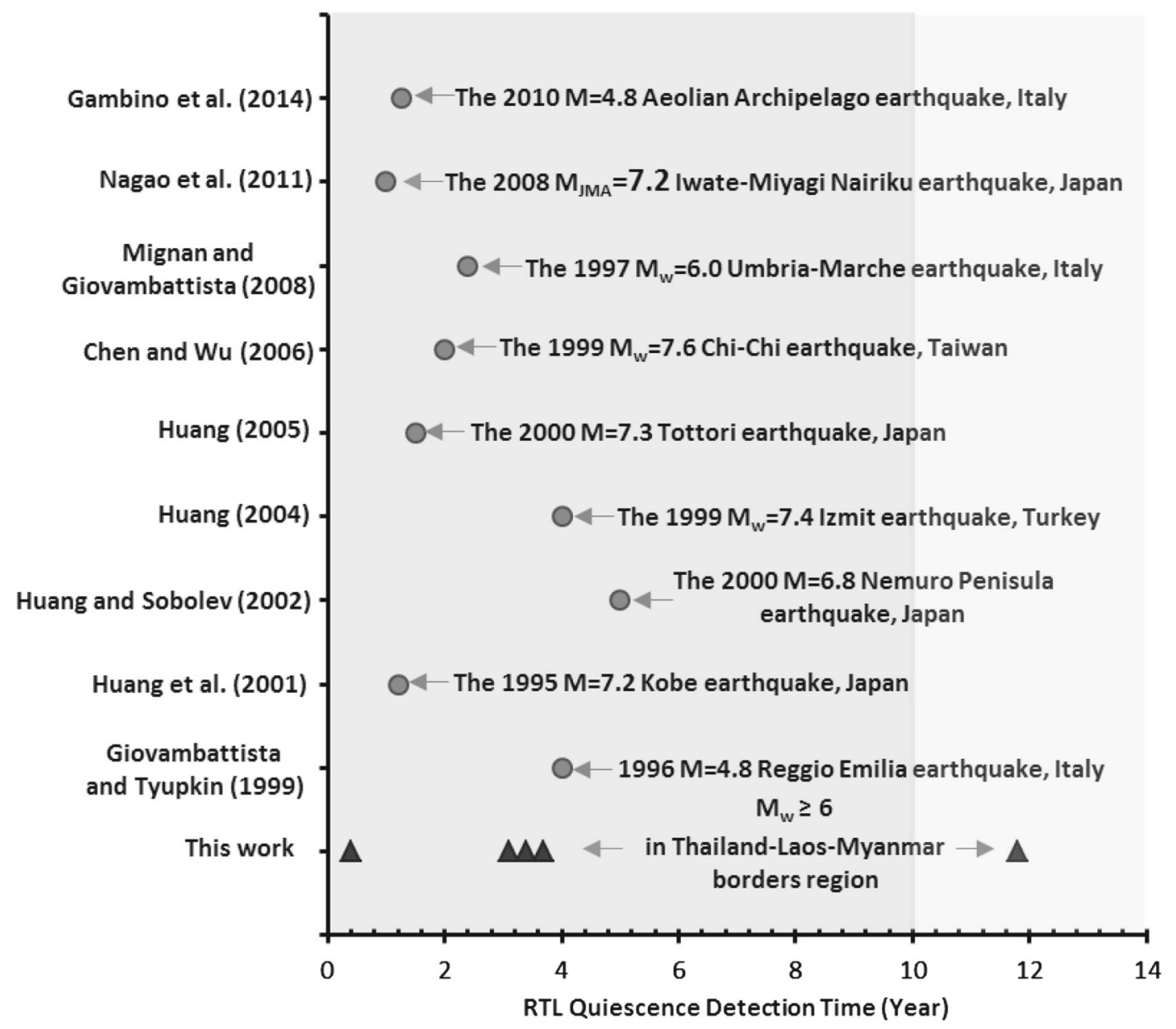

Figure 6. The time span between the occurrence of the precursory seismic quiescence and the following hazardous earthquake, as investigated by the RTL algorithm. The grey circles indicate previous works while triangles denote the results from this study (see also Q-time in table 1).

Sobolev 2002; Huang 2004, 2005; Chen and Wu 2006; Gentili 2010; Gambino et al. 2014), with a time span between the mentioned quiescence and the following earthquake of $1-5$ yr (figure 6). With respect to the results obtained in this study, the time span in most cases was $<4 \mathrm{yr}$, with only the $\mathrm{Mw} 6.1$ earthquake on June 23, 2007 that had an 11.8-yr period between quiescence and earthquake occurrence (figure 6). Thus, by using the selected characteristic parameters of $r_{0}=120 \mathrm{~km}$ and time $t_{0}=2 \mathrm{yr}$ for the TLMB region, the anomalies obtained here performed fairly well as an intermediate-term earthquake precursor.

\subsection{Prospective areas of upcoming earthquakes}

In order to constrain the RTL algorithm analyzed in this study, the anomalous RTL score obtained here was compared with the FMD b-value (Pailoplee et al. 2013). Seismotectonically, in the given region and time of interest, a lower RTL score implied a higher level of seismic quiescence. Meanwhile, a lower b-value relates empirically to a higher level of accumulated seismotectonic stress. Comparing the spatial distribution of both the RTL score and the b-value over almost the same time span, the areas showing a comparatively low RTL score (this study) conformed to those with a low b-value (Pailoplee et al. 2013), as shown in figure 4(e and $\mathrm{f})$. The overlapping anomalous areas were mostly located in the triple junction of the TLMB. As mentioned above, there were two hazardous earthquakes that occurred after 2010 in this area: the Mw 6.8 earthquake on March 24, 2011 and the Mw 6.8 earthquake on May 5, 2014. Therefore, both the anomalous areas of the RTL score and those of the FMD b-value (the triple junction of the TLMB, northern part of Chiang Mai and including in the vicinity of Pak Beng dam) are potential sites to act as a precursor of the forthcoming hazardous earthquakes. 


\section{Conclusion}

This study attempted to investigate the precursory seismic quiescence that is exposed prior to the occurrence of subsequent strong-to-major earthquakes at the TLMB using the RTL algorithm. The result is useful for the contribution of a hazard map showing the locations of the prospective areas that might generate the hazardous earthquakes in the future. The obtained results lead to the following five conclusions.

- By applying the most suitable characteristic parameter $\left(r_{0}=120 \mathrm{~km}\right.$ and $\left.t_{0}=2\right)$, the RTL algorithm can reasonably detect the seismic quiescence stage prior to five out of eight strongto-major earthquakes generated.

- According to the temporal investigation, the RTL curves illustrated that the duration time between the mentioned quiescent stage and the occurrence time of strong-to-major earthquakes varied in the range of intermediate-term forecasting.

- Both analyses of the correlation coefficient and stochastic test indicated that the characteristic $r_{0}$ and $t_{0}$ parameters were significant and the anomalous areas of the RTL score distribution were not artifacts arising from to the randomness of the seismicity data.

- The anomalously low RTL scores obtained in this study conform to the areas previously shown to have a comparatively low b-value of the FMD (Pailoplee et al. 2013).

- After 2010, two hazardous earthquakes were generated in this area $(\mathrm{Mw} 6.8$ earthquake on March 24th, 2011 and $\mathrm{M}_{\mathrm{L}}-6.3$ earthquake on May 5th, 2014). Then, the areas with overlapping low RTL and b-value anomalies without any subsequent strong-to-major earthquake occurrence may be at risk of an impending earthquake.

\section{Acknowledgements}

This research was funded by the Ratchadapisek Sompoch Endowment Fund (2017), Chulalongkorn University (760003-CC). Thanks are also extended to $\mathrm{T}$ Pailoplee for the preparation of the draft manuscript. The authors thank the Office of Research Affairs, Chulalongkorn University, for a critical review and improved English. The authors acknowledge thoughtful comments and suggestions by the editors and anonymous reviewers that enhanced the quality of this manuscript significantly.

\section{References}

Charusiri P, Daorerk V, Wongvanich T, Nakapadungrat S and Imsamut S 1999 Geology of the Quadrangle Economic Zone (emphasis on China and Thailand); Technical report, National Research Council of Thailand, Bangkok, Thailand, 189p (in Thai with English abstract).

Chen C and Wu Y 2006 An improved region-time-length algorithm applied to the 1999 Chi-Chi, Taiwan earthquake; Geophys. J. Int. 166 144-147.

Fenton C H, Charusiri P and Wood S H 2003 Recent paleoseismic investigations in northern and western Thailand; Ann. Geophys. 46(5) 957-981.

Gambino S, Laudani A and Mangiagli S 2014 Seismicity pattern changes before the $\mathrm{M}=4.8$ Aeolian Archipelago (Italy) earthquake of August 16, 2010; Sci. World J. 2014 1-8.

Gardner J K and Knopoff L 1974 Is the sequence of earthquakes in southern California, with aftershocks removed, Poissonian? Bull. Seismol. Soc. Am. 64(1) 363-367.

Gentili S 2010 Distribution of seismicity before the larger earthquakes in Italy in the time interval 1994-2004; Pure Appl. Geophys. 167 933-958.

Giovambattista R D and Tyupkin T 1999 Spatial and temporal distribution of seismicity before the Umbria-Marche September 26, 1997 earthquakes; J. Seismol. 4(4) 589598.

Gutenberg B and Richter C F 1944 Frequency of earthquakes in California; Bull. Seismol. Soc. Am. 34 185-188.

Habermann R E 1983 Teleseismic detection in the Aleutian Island Arc; J. Geophys. Res. 88 5056-5064.

Habermann R E 1987 Man-made changes of seismicity rates; Bull. Seismol. Soc. Am. 77 141-159.

Holliday J R, Rundle J B, Tiampo K F, Klein W and Donnellan A 2006 Systematic procedural and sensitivity analysis of the pattern informatics method for forecasting large MN5 earthquake events in southern California; Pure Appl. Geophys., https://doi.org/10.1007/s00024-006-0131-1.

Huang Q 2004 Seismicity changes associated with the 2000 earthquake swarm in the Izu Island region; J. Asian Earth Sci. 26 509-517.

Huang Q 2005 A method of evaluating reliability of earthquake precursors; Chin. J. Geophys. 48(3) 701-707.

Huang Q and Sobolev G A 2002 Precursory seismicity changes associated with the Nemuro peninsula earthquake, January 28, 2000; J. Asian Earth Sci. 21(2) 135-146.

Huang Q, Sobolev G A and Nagao T 2001 Characteristics of the seismic quiescence and activation patterns before the $\mathrm{M}=7.2$ Kobe earthquake, January 17, 1995; Tectonophys. 337(1-2) 99-116

Huang Q, Oncel A O and Sobolev G A 2002 Precursory seismicity changes associated with the $\mathrm{Mw}=7.41999$ August 17 Izmit (Turkey) earthquake; Geophys. J. Int. 151(1) $235-242$. 
Iwakuni M, Kato T, Takiguchi H, Nakaegawa H and Satomura M 2004 Crustal deformation in Thailand and tectonics of Indochina peninsula as seen from GPS observations; Geophys. Res. Lett. 31 L11612, https://doi.org/10.1029/ 2004GL020347.

Jordan T H and Jones L M 2010 Operational earthquake forecasting: Some thoughts on why and how; Seis. Res. Lett. 81(4) 571-574.

Lacassin R A 1998 Replumaz and PH Leloup Hairpin river loops and strike-slip sense inversion of southeast Asian strike-slip faults; Geology 26 703-706.

Mignan A and Giovambattista R D 2008 Relationship between accelerating seismicity and quiescence, two precursors to large earthquakes; Geophys. Res. Lett. 35(15) L15306.

Morley C K 2007 Variations in Late Cenozoic-Recent strikeslip and oblique-extensional geometries, within Indochina: The influence of pre-existing fabrics; J. Struct. Geol. 29 $36-58$.

Nagao T, Takeuchi A and Nakamura K 2011 A new algorithm for the detection of seismic quiescence: Introduction of the RTM algorithm, a modified RTL algorithm; Earth Planets Space 63(3) 315-324.

Ornthammarath T, Muenhong K, Sukkadistand N and Innoi K 2015 Classification and analysis of damaged buildings in Dong Ma Da township following Mae Lao Earthquake on 5 May 2014; The 20th National Convention on Civil Engineering, 8-10 July 2015, Chonburi, Thailand, pp. 1-7.

Pailoplee S and Choowong M 2013 Probabilities of earthquake occurrences in Mainland Southeast Asia; Arab. J. Geosci. 6 4993-5006.

Pailoplee S and Choowong M 2014 Earthquake frequencymagnitude distribution and fractal dimension in Mainland Southeast Asia; Earth Planets Space 6(8) 1-10.

Pailoplee S, Sugiyama Y and Charusiri P 2009 Deterministic and probabilistic seismic hazard analyses in Thailand and adjacent areas using active fault data; Earth Planets Space 61 1313-1325.

Pailoplee S, Channarong P and Chutakositkanon V 2013 Earthquake activities in the Thailand-Laos-Myanmar Border region: A statistical approach; Terr. Atmos. Ocean Sci. 24(4) Part II 721-730.

Polachan S, Pradidtan S, Tongtaow C, Janmaha S, Intrawijitr K and Sangsuwan C 1991 Development of Cenozoic basins in Thailand; Mar. Petrol. Geol. 8 84-97.

Simons W J F, Socquet A, Vigny C, Ambrosius B A C, Abu S H, Promthong C, Subarya C, Sarsito D A, Matheussen
S, Morgan P and Spakman W 2007 A decade of GPS in southeast Asia: Resolving Sundaland motion and boundaries; J. Geophys. Res. 112 B06420, https://doi. org/10.1029/2005JB003868.

Sobolev G A 1995 Fundamental of Earthquake Prediction; Electromagnetic Research Center, Moscow, 162p.

Sobolev G A and Tyupkin Y S 1997 Low-seismicity precursors of large earthquakes in Kamchatka; Volc. Seismol. 18 433-446.

Sobolev G A and Tyupkin Y S 1999 Precursory phases, seismicity precursors, and earthquake prediction in Kamchatka; Volc. Seismol. 20 615-627.

Tiampo K F and Shcherbakov R 2011 Seismicity-based earthquake forecasting techniques: Ten years of progress; Tectonophys. 522-523 89-121.

Wang Y, Lin Y-N N, Simons M and Tun S T 2014 Shallow rupture of the 2011 Tarlay earthquake $\left(M_{w} 6.8\right)$, eastern Myanmar; Bull. Seismol. Soc. Am. 104(6) 2904-2914.

Wells D L and Coppersmith K J 1994 Updated empirical relationships among magnitude, rupture length, rupture area, and surface displacement; Bull. Seismol. Soc. Am. 84 974-1002.

Wiemer S 2001 software package to analyze seismicity: ZMAP; Seismol. Res. 72 373-382.

Wiemer S and Wyss M 1994 Seismic quiescence before the Landers $\mathrm{M}=7.5$ and Big Bear $\mathrm{M}=6.51992$ earthquakes; Bull. Seismol. Soc. Am. 84 900-916.

Woessner J and Wiemer S 2005 Assessing the quality of earthquake catalogues: Estimating the magnitude of completeness and its uncertainty; Bull. Seismol. Soc. Am. 95(2) 684-698.

Wyss M 1991 Reporting history of the central Aleutians seismograph network and the quiescence preceding the 1986 Andreanof Island earthquake; Bull. Seismol. Soc. Am. 81 1231-1254.

Yadav R B S, Tripathi J N, Shanker D, Rastogi B K, Das M C and Kumar V 2011 Probabilities for the occurrences of medium to large earthquakes in northeast India and adjoining region; Nat. Hazards 56 145-167.

Zuchiewicz W, Cuong N Q, Bluszcz A and Michalik M 2004 Quaternary sediments in the Dien Bien Phu fault zone, NW Vietnam: A record of young tectonic processes in the light of OSL-SAR dating results; Geomorphology 60269 302.

Zúñiga F R, Reyes M A and Valdés C 2000 A general overview of the catalog of recent seismicity compiled by the Mexican Seismological Survey; Geofís. Int. 39(2) $161-170$. 